\section{Errors leading to unexpected pseudophakic ametropia}

\section{L.F.F. Smith \\ J.D. Stevens \\ F. Larkin \\ M. Restori \\ Moorfields Eye Hospital London EC1V 2PD, UK \\ Miss Lindsey F.F. Smith Conclusions Most cases of serious unintended ametropia after cataract surgery are avoidable. Care should be taken with the biometry and procedural checks to minimise error. When lens implant exchange or LASIK was performed the final refractive results were}

FRCOphth

Moorfields Eye Hospital

162 City Road

London EC1V 2PD, UK

Tel: +44 (0)20 72514835

Fax: $+44(0) 2075662608$

e-mail:

101506.1271@compuserve.com

This research has been Research \& Ethics

Committee approved at Moorfields Eye Hospital, project ref. 660

Received: 4 April 2001 Accepted in revised form: 13 August 2001

Key words Ametropia, Biometry error, Cataract surgery, Human, Intraocular lens exchange, LASIK

Unexpected refractive outcomes following intraocular lens implantation have been reported due to spherical ametropia resulting from biometry errors ${ }^{1}$ and high astigmatism due to issues of wound construction or suturing. ${ }^{2}$ Sutureless small-incision surgery has reduced unexpected post-surgery woundrelated astigmatism, ${ }^{3,4}$ but the problem of unplanned high spherical error remains. Until

\begin{abstract}
Purpose Determination of the reasons for clinically significant unplanned ametropia following cataract surgery and the results of management of the ametropia.

Methods Retrospective review of 11 consecutive cases of tertiary referral for management of pseudophakic ametropia to the authors. Corrective surgery involved either lens implant exchange or LASIK refractive surgery. Final outcome was assessed by uncorrected and best spectacle corrected visual acuity and manifest refractive outcome.

Results Five cases $(45 \%)$ were due to significant error in axial length determination at pre-surgery biometry. Six cases $(55 \%)$ were due to surgeon or surgical team error, where the surgeon implanted a lens of power at variance with that specified pre-operatively. Nine patients elected to undergo refractive surgery to correct the ametropia and 2 elected to wear a spectacle lens. Seven underwent lens implant exchange and 2 patients underwent LASIK keratorefractive surgery. Eight of nine patients were within 1 dioptre of intended spherical equivalent after refractive surgery and 1 patients was -1.5 dioptre myopic. satisfactory.
\end{abstract}

LINDSEY F.F. SMITH, JULIAN D. STEVENS, FRANK LARKIN, MARIE RESTORI recent innovations in optical biometry, ${ }^{5}$ most measurement prior to cataract surgery has assessed axial length ( $\mathrm{AL}$ ) using desk-top A-scan ultrasound and corneal power using Javal-Schiotz or von Helmholtz keratometry. B-scan AL determination is often performed when A-scan results are unreliable, ${ }^{6}$ in particular where there is high myopia and where a posterior staphyloma is present. For the majority of patients, when biometry is performed by experienced personnel the results are good. ${ }^{7}$ However, in some cases there is failure in the biometry process, or errors are made at surgery, such that the patient has an unintended spherical refractive result.

Only a minority of intraocular lens (IOL) exchange procedures are performed for incorrect lens power. Brown and Snead ${ }^{8}$ reviewed 23 cases of lens exchanges and found that inappropriate power was the cause for removal in $4(17 \%)$ cases. They concluded the source of error was the AL measurement. An extensive survey ${ }^{9}$ of 1087 lens explantation procedures among members of the American Society of Cataract and Refractive Surgeons in 1984, found incorrect lens power as the reason for $13 \%$ of explanted posterior chamber lenses, most of the remainder being necessitated by lens malposition. A further study ${ }^{1}$ revealed that post-implant refractive errors ranged from +4.37 to -14.0 dioptres (D). They concluded that most of these errors were caused by errors in the AL measurement or in the subsequent calculation of implant power.

Potential sources of error in IOL power selection include incorrect AL measurement, incorrect corneal power determination, and error resulting from use of inappropriate IOL calculation formulas in eyes with unusually long or short AL. Insertion of an inappropriate IOL at surgery, or surgeon-specific factors such as wound construction technique, can also produce an unanticipated refractive result. ${ }^{10}$

We examine here the causes of refractive error in 11 consecutive patients referred with clinically significant unintended spherical refractive outcome after cataract surgery. On account of significant symptoms, all patients required further optical or surgical 


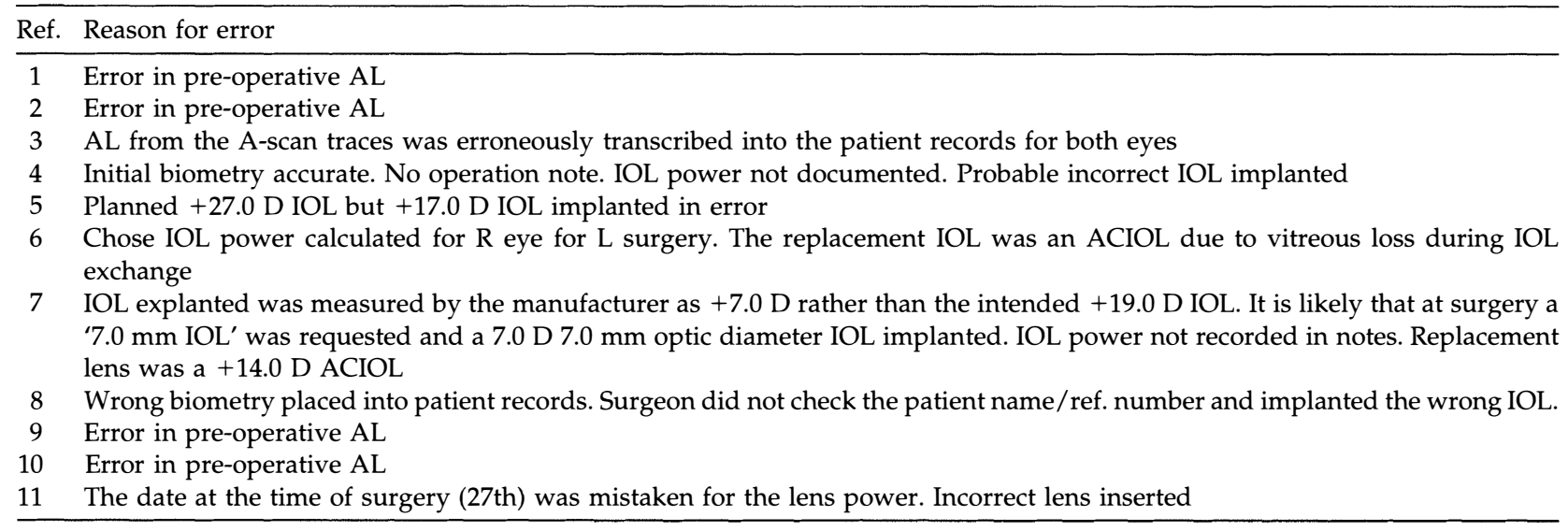

$\mathrm{AL}$, axial length; IOL, intraocular lens; $\mathrm{ACIOL}$, anterior chamber IOL.

management. Virtually all cases of unintended refractive outcome are avoidable. This paper highlights the factors contributing to such errors and new options in their refractive management.

\section{Methods}

A retrospective review was performed of all patients referred over a 6 month period with unexpected refractive outcomes following cataract surgery. Preoperative biometry data were recorded together with repeat measurements following referral. The method of optical correction was noted and the refractive outcome following subsequent management was compared with that following the initial cataract surgery.

Ultrasound and partial coherence interferometric (PCI) axial length measurement was performed when patients were referred using adjustments to the biometry due to the pseudophakia. For each patient the lens implant style with knowledge of the optic material was used to make the necessary adjustment to the A-scan and B-scan biometry and for the PCI (IOL Master, Carl Zeiss Instruments) biometry. Each adjustment was a 'standard' adjustment to the software of these instruments.
In one case where there was no operation note we calculated the probable lens power by measuring the lens optic central thickness by perfoming in vivo ultrasound and comparing this with lenses of the same model in a water bath. A direct comparison was then made with a lens of the same optic thickness. The lens was then explanted and sent to the manufacturer (Bausch \& Lomb, Rochester, NY, USA) for confirmation of the explanted lens power and this was performed in a masked fashion, without the lens manufacturer being informed of the ultrasound calculated power at Moorfields Eye Hospital.

All patients were offered options for optical vision correction by spectacle or contact lens, or surgical intervention was considered. Surgical intervention involved either lens implant exchange or LASIK keratorefractive surgery. LASIK was chosen when there had been at least 12 weeks between referral and the original cataract surgery, where there was a significant astigmatic error and there was no glaucoma. LASIK was performed rather than lens exchange where the refractive error was less than $+4.0 \mathrm{D}$ hyperopia and where there was less than $-6.5 \mathrm{D}$ myopic sphere. LASIK was performed using a VISX Star S2 laser system with version 3.1 software and a Chiron Hansatome microkeratome.

Table 2. Patient evaluation and measurements prior to original cataract surgery

\begin{tabular}{|c|c|c|c|c|c|c|c|c|}
\hline Ref. & $\begin{array}{l}\text { Pre-cataract } \\
\text { surgery } \\
\text { refraction }\end{array}$ & $\begin{array}{l}\text { Axial length } \\
\text { technique }\end{array}$ & $\begin{array}{l}\text { Axial length } \\
\text { measured }\end{array}$ & Keratometry & $\begin{array}{c}\text { Target } \\
\text { refractive } \\
\text { outcome }\end{array}$ & $\begin{array}{l}\text { Both eyes } \\
\text { measured? }\end{array}$ & $\begin{array}{c}\text { Predicted lens } \\
\text { power for } \\
\text { emmetropia }\end{array}$ & $\begin{array}{l}\text { Lens power } \\
\text { implanted (D) }\end{array}$ \\
\hline 1 & $-9.50 /-0.75 \times 180$ & A-scan & 31.10 & $46.25,45.25$ & -0.86 & Yes & -4.85 & -3.0 \\
\hline 2 & Not performed & A-scan & 21.74 & $43.25,43.25$ & +0.07 & Yes & 25.6 & 25.5 \\
\hline 3 & Not performed & A-scan & 23.34 & $46.50,46.00$ & -0.46 & Yes & 18.78 & 19.5 \\
\hline 4 & Not performed & B-scan & 25.50 & $44.50,43.25$ & -0.32 & No & 14.49 & 15.0 \\
\hline 5 & $+4.00 /-1.00 \times 90$ & A-scan & 21.42 & $44.75,43.50$ & -0.58 & No & 26.71 & 17.0 \\
\hline 6 & $+1.00 /-1.25 \times 97$ & A-scan & 24.00 & $42.50,42.50$ & -0.51 & Yes & 20.77 & 27.0 \\
\hline 7 & Not performed & A-scan & 24.74 & $44.11,41.30$ & -0.21 & No & 18.19 & No record \\
\hline 8 & Not performed & A-scan & $\begin{array}{c}\text { Incorrect } \\
\text { patient data }\end{array}$ & $\begin{array}{c}\text { Incorrect } \\
\text { patient data }\end{array}$ & -0.50 & Yes & $\begin{array}{c}\text { Not } \\
\text { applicable }\end{array}$ & 18.0 \\
\hline 9 & $+2.25 /-1.50 \times 7$ & A-scan & 22.00 & $42.45,42.45$ & -0.26 & Yes & 23.67 & 24.0 \\
\hline 10 & $-3.00 /-0.50 \times 90$ & A-scan & 21.74 & $45.86,44.70$ & -0.57 & Yes. & 24.29 & 25.0 \\
\hline 11 & Not performed & A-scan & Not available & Not available & Unknown & Unknown & Unknown & 27.0 \\
\hline
\end{tabular}


Table 3. Variables at cataract surgery

\begin{tabular}{rlll}
\hline Ref. & Lens optic diameter $(\mathrm{mm})$ & Grade of surgeon & Intraoperative complications \\
\hline 1 & PMMA 5.5 & Consultant & $\mathrm{Nil}$ \\
2 & Foldable 5.5 & Resident supervised & $\mathrm{Nil}$ \\
3 & Injectable 6.0 & Consultant & $\mathrm{Nil}$ \\
4 & Injectable 6.0 & Resident unsupervised & Nil. No surgical note \\
5 & PMMA 7.0 & Consultant & Nil. Incorrect lens implanted in error \\
6 & Injectable 6.0 & Fellow unsupervised & Implanted 27 D lens in error \\
7 & PMMA 7.0 & Resident unsupervised & Vitreous loss. Incorrect lens implanted in error \\
8 & Injectable 6.0 & Fellow unsupervised & Nil \\
9 & Foldable 5.5 & Consultant & Nil \\
10 & Foldable 5.5 & Consultant & Nil \\
11 & Foldable 5.5 & Resident & Incorrect lens implanted in error \\
\hline
\end{tabular}

\section{Results}

Diverse causes of post-operative refractive error were identified in this cohort (Table 1). The evaluation of patients prior to primary cataract surgery and target spherical equivalent outcome of the original surgeon is summarised in Table 2.

Of the 11 patients referred with significant postoperative refractive error, the reason in 5 cases was incorrect AL measurement (Table 2). In another 6 cases the surgeon implanted a lens of power at variance with that specified pre-operatively. Primary surgery was performed by 6 surgeons in training and included 5 of the 6 cases in which intra-operative errors accounted for the ametropic outcome (Table 3). Spherical ametropia following cataract surgery ranged from -6.12 to $+6.75 \mathrm{D}$ spherical equivalent (Table 4). Patients were managed by lens implant exchange in 7 cases, LASIK in 2 cases and spectacle correction in 2 cases (Table 4). In those patients managed by IOL exchange or LASIK, final refractive and visual outcomes were good. It is of interest that no cystoid macular oedema or significant intraocular inflammation occurred (Table 5). We identified no significant keratometry errors.

In one case the measurements for another patient were erroneously placed into the clinical notes of the patient for surgery. The reasons for implanting a lens power differing from that specified pre-surgery included transcription error (incorrect copying down of the measurements from the biometry print-out to the patient's clinical notes), the lens appropriate for the right eye being implanted into the left eye, and surgical complication, where a different style of lens was implanted with an error in lens dioptric power.

All but one of the errors could be identified by repeat measurement of AL and corneal power. In case 4 there was no operation note or record of the lens implanted and it was necessary to measure the explanted lens optic power in vitro using the ultrasound lens optic thickness method described above. The measured lens power at Moorfields Eye Hospital was between 7 and $9 \mathrm{D}$, and the manufacturer of the lens calculated the lens power to be $7 \mathrm{D}$ using an optical power measurement in vitro.

As can be seen from this series, these patients were managed by optical vision correction, lens implant exchange or LASIK keratorefractive surgery. Spectacle correction may be sufficient in some individuals who choose not to undergo any further surgical intervention, though most patients were referred for surgical intervention since they were unhappy with their optical situation following cataract surgery. No patient chose contact lens wear, possibly reflecting the older age of this patient group who have undergone cataract surgery. IOL exchange is a further intraocular surgical procedure. One patient in our series suffered vitreous loss during IOL

Table 4. Clinical outcomes and management following cataract surgery

\begin{tabular}{|c|c|c|c|c|c|}
\hline Ref. & $\begin{array}{l}\text { Weeks } \\
\text { post-surgery }\end{array}$ & $\begin{array}{l}\text { Post-operative } \\
\text { spherical } \\
\text { equivalent (D) }\end{array}$ & $\begin{array}{l}\text { Post-operative } \\
\text { UCVA }\end{array}$ & $\begin{array}{l}\text { Post-operative } \\
\text { BSCVA }\end{array}$ & Action taken \\
\hline 1 & 3 & +4.50 & $6 / 60$ & $6 / 5$ & $\begin{array}{l}\text { Repeat biometry by B-scan and Holladay } 2 \text { formula, then lens } \\
\text { exchange }\end{array}$ \\
\hline 2 & 41 & -6.00 & $3 / 60$ & $6 / 6$ & Repeat biometry, then lens exchange \\
\hline 3 & 3 & +1.50 & $6 / 24$ & $6 / 6$ & $\begin{array}{l}\text { Repeat biometry, 'advised regarding hyperopic LASIK, remains } \\
\text { wearing glasses }\end{array}$ \\
\hline 4 & 3 & +5.25 & $6 / 24$ & $6 / 9$ & $\begin{array}{l}\text { Only eye, patient continues to wear spectacles, declined further } \\
\text { surgery }\end{array}$ \\
\hline 5 & 3 & +5.50 & $6 / 60$ & $6 / 18$ & Lens exchange, biometry not repeated \\
\hline 6 & 10 & -6.00 & $3 / 60$ & $6 / 9$ & Lens exchange, biometry not repeated \\
\hline 7 & 2 & +6.75 & $6 / 36$ & $6 / 6$ & $\begin{array}{l}\text { Repeat biometry, then lens explantation, then secondary lens } \\
\text { implantation }\end{array}$ \\
\hline 8 & 24 & +6.00 & $3 / 60$ & $6 / 9$ & Repeat biometry, then lens implant exchange \\
\hline 9 & 12 & -2.88 & $6 / 60$ & $6 / 12$ & Repeat biometry, then LASIK \\
\hline 10 & 12 & -4.13 & $<3 / 60$ & $6 / 6$ & Repeat biometry, then LASIK \\
\hline 11 & 24 & -6.12 & $<3 / 60$ & $6 / 6$ & Repeat biometry, then lens exchange \\
\hline
\end{tabular}

UCVA, uncorrected visual acuity; BSCVA, best spectacle corrected visual acuity. 


\begin{tabular}{rccccccc}
\hline Ref. & $\begin{array}{c}\text { Repeat axial } \\
\text { length A-scan }\end{array}$ & $\begin{array}{c}\text { Post-operative } \\
\text { keratometry }\end{array}$ & $\begin{array}{c}\text { Exchange lens } \\
\text { power (D) }\end{array}$ & $\begin{array}{c}\text { Final refractive } \\
\text { outcome at last } \\
\text { follow-up }\end{array}$ & $\begin{array}{c}\text { Error from } \\
\text { intended (D) }\end{array}$ & Final UCVA & Final BSCVA \\
\hline 1 & 27.70 & $46.4,45.4$ & +5.00 & $0.00 /-1.00 \times 100$ & -0.3 & $6 / 9$ & $6 / 5$ \\
2 & 24.12 & $43.2,42.5$ & +19.50 & $-0.50 /-1.75 \times 80$ & -1.5 & $6 / 36$ & $6 / 6$ \\
3 & 22.68 & $46.0,45.1$ & - & $+2.00 /-1.00 \times 60$ & & $6 / 24$ & $6 / 6$ \\
4 & 24.74 & $44.8,43.4$ & - & $+6.00 /-1.50 \times 25$ & & $6 / 24$ & $6 / 9$ \\
5 & Not done & Not done & +27.0 & $-0.75 /-1.00 \times 5$ & -1.0 & $6 / 9$ & $6 / 9$ \\
6 & Not done & Not done & +17.0 ACIOL & $0.00 /-2.25 \times 95$ & -0.8 & $6 / 60$ & $6 / 9$ \\
7 & 25.20 & $45.0,42.0$ & +14.0 ACIOL & $0.00 /-1.25 \times 70$ & +0.4 & $6 / 18$ & $6 / 9$ \\
8 & 22.93 & $49.5,48.8$ & +27.0 & $+0.25 /-1.25 \times 15$ & +0.2 & $6 / 18$ & $6 / 9$ \\
9 & 24.03 & $43.5,41.8$ & (LASIK) & 0.00 & 0.0 & $6 / 5$ & $6 / 5$ \\
10 & 23.75 & $45.6,43.4$ & (LASIK) & $+0.25 /-0.25 \times 170$ & 0.12 & $6 / 6$ & $6 / 5$ \\
11 & 23.65 & $45.0,44.0$ & +19.0 & $+0.25 /-0.50 \times 15$ & 0.0 & $6 / 6$ & $6 / 5$ \\
\hline
\end{tabular}

UCVA, uncorrected visual acuity; BSCVA, best spectacle corrected visual acuity.

exchange. The main surgical technical issue with late lens explantation is capsular bag fibrosis, which can make explantation or implantation of the replacement lens into the capsular sac difficult. A lens implant placed with sulcus fixation has less optical predictability than in-thebag fixation due to variation in final antero-posterior positioning.

\section{Discussion}

Accurate lens implant power calculation requires an understanding of the biometry process and involves a multi-step approach. Each component of biometry is associated with possible errors of assessment. The AL, keratometry, horizontal white-to-white distance and anterior chamber depth are all components of modern biometric formulae. ${ }^{11}$ The choice of the correct formula for a given eye is also important. ${ }^{12}$ It is inappropriate to choose a formula optimised for short AL eyes in a high myope or vice versa.

Nine patients underwent refractive surgery in this series for the unintended ametropia, of whom 8 were within $1 \mathrm{D}$ of the intended refractive outcome and all 9 within $1.5 \mathrm{D}$. Outcomes of surgery of pseudophakic ametropia in the cases described were satisfactory, following either lens exchange or keratorefractive laser surgery. The latter is a new option, which requires prospective evaluation.

Corneal laser refractive surgery is an alternative to IOL exchange. It is easiest to perform IOL exchange soon after the initial surgery, as illustrated by case 5 , but corneal refractive surgery requires a period for postcataract wound healing. LASIK currently requires application of a suction ring to the eye for creation of the LASIK flap and this requires the cataract main wound incision to be fully healed. Patients undergoing LASIK underwent the procedure at least 12 weeks after the original cataract surgery. This also ensures refractive stability after the cataract surgery, prior to the keratorefractive procedure. LASIK aimed to correct both the spherical and astigmatic refractive error. Patient 11 could not undergo LASIK for the residual myopia due to glaucoma, which is a contraindication to current LASIK, due to the need to apply a suction ring and risk optic nerve damage. LASIK can be performed for myopic, astigmatic or hyperopic ametropia. It has a place in the management of post-cataract surgery ametropia as an alternative to lens implant exchange or piggyback (secondary) lens implantation ${ }^{13}$ in front of the original lens implant. Piggyback lens implantation requires the secondary lens to be placed either in the sulcus anterior to an in-the-bag lens implant or an anterior chamber lens can be sited. Such lenses require careful centration with respect to the primary posterior chamber lens and it is not possible to site touching lenses if one optic is of soft material as deformation occurs and in addition interoptic opacification can occur. ${ }^{14}$

Cataract surgery is a process involving a team approach and the measurements and checks are undertaken by a variety of different personnel including surgeons, nurses and ultrasound technicians. Teamwork is of paramount importance to prevent medical error and it is important to follow a standardised approach to the choice of lens power as discussed above. Team error ${ }^{15}$ has been defined as action or inaction leading to deviation from team or organisational intentions. The causes of error in our series arise from a variety of personnel and phases in patient management. The grade of surgeon varied from senior (Consultant) in 5 cases to Trainee or Fellow in 6 cases, which demonstrates that the errors were not due to the inexperience of the surgeon performing the operation.

Imperfect information processing and lack of attention to detail on procedural checks have occurred. This included incorrect AL measurement, mistakes in transferring data to the clinical records, faulty checking of the power of the lens implant during surgery and the biometry data of one patient being put into another patient's notes. While clinically significant errors are inevitable in some patients due to the errors inherent in biometry, most serious errors are avoidable without improving biometry technology. To overcome these errors a risk management program should be in place, which would enhance teamwork. Technical training increases proficiency. Team training minimises communication and decision errors, whereas procedural errors may result from human limitations or inadequate procedures. 
In one case in this series, the wrong implant was given to the surgeon and this may have occurred as a result of poor communication, or where lenses for different patients were placed together in the operating room. It is therefore important to have only one lens on the surgical trolley for the patient during surgery and to check the power with the surgeon before opening the lens box.

Based on observations in this case series, we recommend the following practice points. After assessing the patient prior to surgery, it is the responsibility of the surgeon to make a number of pre-surgical checks, which include the following:

1. Check the biometry reading within the patient's record and include a copy of the printout, including name and reference number and eye for surgery.

2. Biometry should be performed in accordance with good procedure, such as both eyes being assessed for comparison, or if surgery is on the second eye then the first eye outcome is recorded and considered. Education of the nursing/technical/medical staff performing these measurements should aim to improve consistency and to alert the surgeon to any difficulties encountered during measurements.

3. Any difference in AL between the two eyes should correlate with the refractive state prior to cataract onset. Axial lengths should be within $0.30 \mathrm{~mm}$ if the refractive state between the eyes is similar prior to cataract development. This criterion is commonly found as standard with many A-scan biometry units since $0.3 \mathrm{~mm}$ axial length difference translates to approximately 1.0 D spherical refractive difference.

4. The keratometry should appear reasonably concordant with ocular astigmatism. If discordant readings are obtained then further assessment should be performed such as automated keratometry or videokeratography, providing objective methods of assessment.

5. The pre-operative refraction should be noted and the refractive target IOL power, type and incision meridian should be clearly documented in the clinical record.

6. The IOL power should be double-checked both in the notes and with the first surgical assistant or scrub nurse.

7. Once the lens implant has been inserted a label should be fixed into the operation notes recording the power of the lens implant.

8. If electronic patient records are in use, transcription errors can be minimised by using direct data output from newer biometry equipment. Use of computerised records systems still requires rigorous checking that data are entered into the correct record, identical to best procedure for paper records.

9. The appropriate biometry formula should be applied for the eye to undergo surgery. Formulae are constantly being updated and improved. At the present time common formulae used for short axial length eyes are Holladay $2,{ }^{16}$ Haigis ${ }^{17}$ and Hoffer Q. ${ }^{16}$ For eyes with axial lengths within the normal range common formulae are SRKT, ${ }^{16}$ Holladay $2^{16}$ and
Hoffer Q. ${ }^{16}$ Long axial length eyes commonly are calculated with SRKT ${ }^{18}$ and L-SRK ${ }^{19}$ formulae. The decision for choice of formula rests with the individual surgeon.

To minimise risk it is important not only for rigorous 'pre-flight' checks to be made by the surgeon and team, but also for proper procedure and training to be in place. Good procedure aims to minimise risk. Patients continue to receive incorrect lens implants and it is very important for procedure to be re-evaluated and implemented.

\section{References}

1. Salz JJ, Reader A. Lens implant exchanges for incorrect power: results of an informal survey. J Cataract Refract Surg $1988 ; 14: 221-4$

2. Jaffe NS, Clayman HM. The pathophysiology of corneal astigmatism after cataract extraction. Trans Am Acad Ophthalmol Otolaryngol 1975;79:615-30.

3. Long DA, Monica ML. A prospective evaluation of corneal curvature changes with 3.0 to $3.5 \mathrm{~mm}$ corneal tunnel phacoemulsification. Ophthalmology 1996;103:226-32.

4. Kohnen T, Burkhard D, Jacobi KW. Comparison of the induced astigmatism after temporal clear corneal tunnel incisions of different sizes. J Cataract Refract Surg 1995;21:417-24.

5. Hitzenberger CK. Optical measurement of the axial length of the eye by laser Doppler interferometry. Invest Ophthalmol Vis Sci 1991;32:616-24.

6. Kendall CJ. Ophthalmic echography. Ophthalmic technical skills series. Thorofare, NJ: Slack, 1991.

7. Restori M. Lens implant power calculation. BMJ 2001; in press.

8. Brown DC, Snead JW. Intraocular lens implant exchanges. Am Intraocular Implant Soc J 1985;11:376-9.

9. Kraff MC, Sanders DR, Raanan MG. A survey of intraocular lens explantations. J Cataract Refract Surg 1986;12:644-50.

10. Carlson AN, Stewart WC, Tso PC. Intraocular lens complications requiring removal or exchange. Surv Ophthalmol 1998;42:417-40.

11. Hoffer KJ. Clinical results using the Holladay 2 intraocular lens power formula. J Cataract Refract Surg 2000;26:1233-7.

12. Fenzi RE, Gills JP, Cherchio M. Refractive and visual outcome of hyperopic cataract cases operated on before and after implementation of Holladay 2 formula. Ophthalmology 1998;105:1759-64.

13. Masket S. Piggyback intraocular lens implantation. J Cataract Refract Surg 1998;24:569-70.

14. Eleftheriadis H, Marcantonio J, Duncan G, Liu C. Interlenticular opacification in piggyback AcrySof intraocular lenses: explantation technique and laboratory investigations. Br J Ophthalmol 2001;85:830-6.

15. Helmreich RL. On error management: lessons from aviation. BMJ 2000;320:781-5.

16. Hoffer KJ. Clinical results using the Holladay 2 intraocular lens power formula. J Cataract Refract Surg 2000;26:1233-7.

17. Haigis W, Lege B, Miller N, Schneider B. Comparison of immersion ultrasound biometry and partial coherence interferometry for intraocular lens calculation according to Haigis. Graefes Arch Clin Exp Ophthalmol 2000;238:765-73.

18. Findl O, Drexler W, Menapace R, Heinzl H, Hitzenberger $\mathrm{CK}$, Fercher AF. Improved prediction of intraocular lens power using partial coherence interferometry. J Cataract Refract Surg 2001;27:861-7.

19. Kijima T, Kozawa T, Kora Y, Yaguchi S, Inatomi M, Koide R, Ozawa T. Accuracy of intraocular power calculation formulas. Nippon Ganka Gakkai Zasshi 1999;103:470-6. 